\title{
Electrochemical Characteristics of Nickel Hydroxide Fabricated from a Spent Electroless Plating Bath
}

\author{
Tzu-Hsuan Tsai ${ }^{1}$,Hao-Wei Chou ${ }^{1}$, Yung-Fu $W_{u^{2}}{ }^{*}$ \\ ${ }^{1}$ Department of Materials and Mineral Resources Engineering, National Taipei University of \\ Technology, Taipei 10608, Taiwan \\ ${ }^{2}$ Department of Chemical Engineering, Ming Chi University of Technology, New Taipei City 24301, \\ Taiwan \\ *E-mail: gausswu@mail.mcut.edu.tw
}

Received: 11 October 2021 / Accepted: 17 November 2021 / Published: 5 January 2022

Electroless nickel plating baths must be replaced periodically to retain the quality of the deposited nickel film, thus resulting in a considerable amount of spent plating solution. In the spent plating solution, $\mathrm{Ni}^{2+}$ of sufficiently high concentration can be reused for energy storage applications. This study investigated a chemical precipitation method that involved adding sodium hydroxide and polyethylene glycol to generate $0.5-\mu \mathrm{m} \mathrm{Ni}(\mathrm{OH})_{2}$ particles. The electrochemical experimental results indicated that an electrode consisting of $\mathrm{Ni}(\mathrm{OH})_{2}$ and Vulcan $\mathrm{XC} 72$ carbon black could provide active sites for charge storage because of the layered structure of the $\mathrm{Ni}(\mathrm{OH})_{2}$. The interstitial water between the layers enhanced the transport of $\mathrm{H}^{+}$with a diffusivity of $1.4 \times 10^{-12} \mathrm{~cm}^{2} / \mathrm{s}$, which was twice as high as that of an electrode made from commercial $\mathrm{Ni}(\mathrm{OH})_{2}$. Furthermore, a charging-discharging measurement with 100 cycles revealed that the electrode made with $\mathrm{Ni}(\mathrm{OH})_{2}$ from a spent plating bath exhibited $88 \%$ capacitance retention, which was greater than that of the electrode made from the commercial $\mathrm{Ni}(\mathrm{OH})_{2}$. Consequently, the method proposed in this study may provide usable materials for energy storage while removing nickel from spent plating baths.

Keywords: Nickel hydroxide, electroless plating bath, precipitation, energy storage

\section{FULL TEXT}

(C) 2022 The Authors. Published by ESG (www.electrochemsci.org). This article is an open access article distributed under the terms and conditions of the Creative Commons Attribution license (http://creativecommons.org/licenses/by/4.0/). 